\title{
Lifestyle behaviour and prevalence of cardiovascular risk factors - a pilot study comparing Kiribati and European seafarers
}

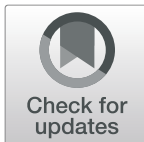

R. von Katzler ${ }^{1 *}$ (D, B. C. Zyriax², B. Jagemann ${ }^{3}$, J. Westenhoefer ${ }^{4}$, H. J. Jensen ${ }^{1}$, V. Harth ${ }^{1}$ and M. Oldenburg ${ }^{*}$

\begin{abstract}
Background: According to internal observations within a German shipping company, obvious risk-behaviour persists among the crew members coming from the Pacific Island State of Kiribati and representing a large part of the crew aboard merchant vessels of this company. These observations were related to excessive eating habits. This study aims to assess the cardiovascular risk among seafarers and to compare lifestyle factors between Kiribati and European crew members.

Methods: In the present maritime field study 81 sailors (48 Kiribati, 33 European, average age at 38.9 and 36.8 years respectively) were examined from April until August 2014 aboard four container ships crossing the Atlantic Ocean (participation rate of $90.9 \%$ ).

Results: Based on the number of established risk factors, $35.4 \%$ of the Kiribati and $16.7 \%$ of the European crew members were regarded as a high risk group for cardiovascular diseases. The HDL-values of Kiribati were found to be considerably lower $(34.9 \mathrm{mg} / \mathrm{dl})$ than the references values given by the $\mathrm{WHO}$ and in comparison to the European crew members $(44.8 \mathrm{mg} / \mathrm{dl})(p=0.002) .91 .7 \%$ of Kiribati and $51.5 \%$ of European participants were found to be overweight according to WHO-criteria - with a mean Body Mass Index (BMI) of $30.3 \mathrm{~kg} / \mathrm{m}^{2}$ and $25.6 \mathrm{~kg} / \mathrm{m}^{2}$ $(p<0.001)$. Regarding lifestyle factors Kiribati often claimed to eat significantly larger amounts of food aboard while most European sailors stated to eat less or about the same during their shipboard stay $(p=0.017)$. Daily sleeping hours were slight on both sides; however with a mean of $5.2 \mathrm{~h}$ a day Kiribati crew members had significant fewer sleep $(p=0.038)$. The examined Kiribati sailors had a mean increase in weight of $6 \mathrm{~kg}$ over a 12 months period of observation.
\end{abstract}

Conclusions: In total the compiled data points towards a higher risk of cardiovascular diseases particularly due to alimentary habits within the Kiribati crew members. The distinct weight-gain measured among the Kiribati in spite of higher energy consumption levels at sea is alarming. Thus, the results of this study confirm the necessity of health-improving interventions aboard cargo vessels.

Keywords: Seafarers, Cardiovascular, Lifestyle, Kiribati, Obesity, Vessels

\footnotetext{
* Correspondence: robertvonkatzler@gmx.de;

marcus.oldenburg@bgv.hamburg.de

${ }^{1}$ Institute for Occupational and Maritime Medicine (ZfAM) Hamburg,

Seewartenstr, 10, 20459 Hamburg, Germany

Full list of author information is available at the end of the article
}

C The Author(s). 2019 Open Access This article is distributed under the terms of the Creative Commons Attribution 4.0 International License (http://creativecommons.org/licenses/by/4.0/), which permits unrestricted use, distribution, and reproduction in any medium, provided you give appropriate credit to the original author(s) and the source, provide a link to the Creative Commons license, and indicate if changes were made. The Creative Commons Public Domain Dedication waiver (http://creativecommons.org/publicdomain/zero/1.0/) applies to the data made available in this article, unless otherwise stated. 


\section{Background}

Obesity is one of the well-known risk factors for cardiovascular diseases. Over the last years, research in Poland, France, Norway and Germany has repeatedly shown that cardiovascular risk factors like obesity, smoking, nonHDL-cholesterol, lack of movement and unfavourable eating habits are often prevalent among sailors [1-5].

Literature on cardiovascular risk factors among seafarers is abundant, however the focus often only lies on European sailors. The review by Pougnet et al. (2013), which comprises 18 publications on the subject of cardiovascular risk factors in sailors, included a total of 57,473 subjects, of which only 327 were of nonEuropean origin [6].

Crew members staying aboard cargo vessels for several months at a stretch have very little influence on the quality and diversity of their nutrition. The rare opportunities for shore leave hinder them in buying their own more diverse grocery supplies. Hence, seafarers' nutrition depends mainly on the food provided on board, which has often been described as a high-fat diet. Babicz-Zielinska and Zabrocki (1998) [7] as well as Lawrie et al. (2004) [8] observed that the main dishes aboard cargo ships mostly consist of meat. Conditions aboard, such as diverse eating habits of a mostly multinational crew, the division into officer and crew mess rooms as well as the constantly changing work schedules increase the difficulties of regulating a healthy diet [9], a circadian rhythm and regular physical activities even more. Although balanced nutrition at sea has become a bigger issue in the public discussion, there are still very few indepth studies on this matter [10].

From a medical point of view, the population of Kiribati features characteristics specific to the Pacific island state $[11,12]$. In 2015, 39.3\% of the male Kiribati population was classified as obese [13]. In comparison, according to OECD (2012) [14], 16.5\% of the European population was considered as obese. The past decades have shown a trend towards adiposity in many developing countries. Imported nutritional goods, such as canned and pre-packaged convenience foods, are a crucial reason for this development. Studies have shown that the diet of the Kiribati is characterised by an extremely low intake of essential omega- 6 fatty acid, whereas the consumption of saturated fatty acids is excessively high [15].

In the last couple of years, the shipping company allocating the four cargo vessels for this study received reports about impairments of health due to cardiovascular symptoms while at sea. This seems to be a crucial problem, particularly among the Kiribati crew members. The question of whether these health restrictions could be caused by malnutrition and the observed weight gain during the time on board was discussed.
This study aims at analysing the cardiovascular health status of crew members at sea, especially with respect to lifestyle-related risk factors and in a comparison between Kiribati and European sailors.

\section{Methods}

The 81 seafarers participating in this study came from four cargo vessels belonging to a shipping company with numerous Kiribati crew members. All explored ships were container ships of similar size (mean 99,400 gross tonnage) on a transatlantic route. The participation rate for this study was $90.9 \%$ (five women, four Africans and one person of Asian origin were excluded from the analysis due to statistical reasons). This resulted in two homogenous male cohorts: 48 participants with a Kiribati origin and 33 Europeans. Participation in this study was voluntary (participation rate 90.9\%) and all personal data were pseudonymised. Participants gave their informed consent and the Ethics Committee of the Hamburg Medical Association approved this study. The study was conducted according to good clinical practice based on the Helsinki declaration. The research is also registered within the German Registry of Clinical Studies under the DRKS-ID: DRKS00010819.

\section{Medical examination of sailors}

In terms of a maritime field study, a physician examined and analysed the above-mentioned seafarers in the course of more than 100 days at sea.

\section{Survey questionnaire}

The sailors were asked about their demographic, lifestyle and occupational data. Furthermore, the Perceived Stress Scale used allowed for an assessment of their subjective stress level. Various studies have shown that higher values of this scale correlate with an increased risk of certain diseases [16, 17]. There are no explicit cut-off values for analysis of the Perceived Stress Scale. According to a prior large population study $(n=2387)$ [18], participants with values of 20 points and above were regarded in this study to have an elevated stress level.

\section{Anthropometrics}

The determination of anthropometric values (height and weight) aboard the vessels took place solely during the ships' stay in port to ensure that movements of the ships could not impact the measured values. Weight measurements were performed with a calibrated Kern ${ }^{\circledR}$ scale on participants wearing lightweight clothing and in a sober state. Waist circumference was measured at the midpoint between the bottom of the ribs (lower costal margin) and the top of the hip bone (iliac crest), while the participant was in the standing position during a normal breath out using a non-stretch tape. To assess weight development 
among the Kiribati crew members up to the current shipboard examination, information about weight and height was obtained from their prior medical fitness tests ashore. The determined weight changes mainly refer to the duration of stay on board the current vessels.

\section{Blood pressure measurements}

Blood pressure was measured with acouophonia, taking measurements on each sailor's upper arm with a pressure sleeve from Boso $^{\circ}$. All subjects underwent at least three measurements per day (morning, midday and evening) in a seated position. The average of all individual measurements was calculated for the analysis.

\section{Measuring blood parameters}

Venepuncture was carried out among all subjects in a fasting state $(\mathrm{min} .10 \mathrm{~h})$ in the morning of various days. After a 30-min storage period, the filled blood tubes (S-Monovette $^{\circ}$ serum gel by Sarstedt ${ }^{\circ}$ ) were centrifuged for $10 \mathrm{~min}$ at $2000 \mathrm{x} \mathrm{g}$ in a Sarsted ${ }^{\circ}$ LC-6 centrifuge and immediately stored at $-18^{\circ}$ Celsius in a lightproof storage unit.

After completion of the voyage and in compliance with the cold chain, the following blood parameters were determined in a German laboratory (Lademannbogen GmbH, Hamburg, Germany): cholesterol, HDL, nonHDL-cholesterol, LDL, LDL/HDL ratio, triglyceride, alkaline phosphatase, uric acid and fasting glucose. The analysis of all results referred to reference values from German population studies as no reference values were available for Kiribati in the literature.

\section{Assessment of cardiovascular risks}

A number of parameters are available for assessing population-based cardiovascular risk scores. However, several studies have shown that the calculation of a 10year probability of a heart attack is very imprecise when applied to a group comprising different nationalities [19].

Although the internationally well-known cardiovascular risk factors appear to have a somewhat different relevance within various populations, it can be assumed that they form a valuable basis for the estimation of the general cardiovascular risk [20,21]. For this risk assessment, 8 internationally established risk factors were used for the entire group (age $\geq 45$ years, LDL cholesterol $\geq 160$ $\mathrm{mg} / \mathrm{dl}$, active smokers, HDL cholesterol $\leq 40 \mathrm{mg} / \mathrm{dl}$, blood pressure $\geq 140 / 90 \mathrm{mmHg}$, familiar predispositions, fasting blood glucose levels $\geq 110 \mathrm{mg} / \mathrm{dl}$ and triglyceride $\geq 150 \mathrm{mg} / \mathrm{dl}$ ) according to the National Cholesterol Education Program III (NCEP 2001) [22]. Corresponding to the study by Oldenburg et al. (2008) [23], in the present study one point was equally assigned to each factor. Therefore, values from 0 to 8 could be obtained by summation of the risk factors (RF). The participants were grouped into categories of either low $(<3 \mathrm{RF})$ or high ( $\geq 3 \mathrm{RF}$ ) cardiovascular risk according to this individual rating system. This type of risk evaluation is not as specific as the application of risk scores for a certain population. However, it provides a suitable possibility to compare two culturally different collectives.

\section{Endurance performance capacity}

The Chester Step Test was conducted in order to ascertain the seafarers' endurance performance capacity. This test correlates highly with the medical gold standard of ergospirometry $(r=0.92 ; p<0.001)$ [24]. It is a multi-level submaximal exercise test used to assess age-related physical fitness. This test estimates the individual oxygen uptake rate $\left(\mathrm{VO}_{2}\right)$ in $\mathrm{ml}$ per $\mathrm{kg}$ bodyweight per minute according to well-evaluated mathematical equations $[25,26]$. In compliance with the Chester Step Test specifications, one of the four possible step heights was chosen prior to the exercise as a suitable individual stress level. A sternum strap (T37) by Polar ${ }^{\circ}$ was applied to monitor the participants' heart rates continuously.

\section{Activity monitoring}

The seafarers' physical activity was examined with the Bodymedia SenseWear ${ }^{\bullet}$ armband monitor carried on the left upper arm. Each participating sailor wore this monitor for roughly $200 \mathrm{~h}$. Its internal sensors include an accelerometer, a thermal flow sensor, a galvanic sensor that records skin response, a skin temperature sensor, and an air temperature sensor. The accelerometer in the armband has two axes and uses a microelectromechanical sensor that measures movement. The software created by the manufacturer calculates energy expenditure using a patented algorithm that combines acceleration, heat flow, and other parameters. This device provided information on the total energy expenditure, the active energy expenditure, daily number of steps and duration of sleep periods [27]. Simultaneously, the subjects kept records on their current activities (working, leisure and sleeping time) in daily protocols. By means of these records, cumulative measurement values of the armband monitor could be assigned to certain activities on a daily basis.

\section{Statistics}

The statistical analysis was conducted with the statistics program SPSS 20 (IBM Corporation). A comparison of the two groups (Kiribati vs European) was performed with the Mann-Whitney U Test. Significant differences in frequency between the two groups were analysed through the Chi-Square Test or, in the case of a smaller number of incidents, with the Exact Test according to Fisher. The level of significance was $\leq 0.05$. 


\section{Results}

\section{Study population}

Two homogenous male cohorts were examined: 48 participants with a Kiribati origin and 33 Europeans (age range of the Kiribati: 23-64 years; European: 2061 years). The average age of the Kiribati ( 38.9 years) was insignificantly higher than that of the Europeans (36.8 years).

\section{Anthropometrics}

Even though the Kiribati crew members had a smaller average body height, their median BMI was significantly higher than that of European participants (30.4 (SD \pm $4.2) \mathrm{kg} / \mathrm{m}^{2}$ vs $\left.25.6(\mathrm{SD} \pm 3.4) \mathrm{kg} / \mathrm{m}^{2}\right)(p<0.019)$. According to classifications by the WHO, $91.7 \%$ of the Kiribati and $51.5 \%$ of the control group were overweight (BMI $\geq$ $25 \mathrm{~kg} / \mathrm{m}^{2}$ ). While nearly half of the Kiribati groups were classified as obese $\left(\mathrm{BMI} \geq 30 \mathrm{~kg} / \mathrm{m}^{2}\right)$, only $9.1 \%$ of the Europeans were assigned to this classification. Two Kiribati had a BMI above $40 \mathrm{~kg} / \mathrm{m}^{2}$, which correlates with obesity class 3 . The mean waist circumference of the Kiribati was also significantly larger than that of the Europeans ( $97.5 \mathrm{~cm}$ vs. $92.2 \mathrm{~cm} ; p=0.045$ ).

As shown in Fig. 1, the average Europeans' BMI grew constantly with increasing age. In contrast, the Kiribati demonstrated a significant gain in weight among seafarers older than 30 years of age compared to the younger ones. The youngest age group had an almost normal weight median according to WHO criteria, with an average BMI of $26 \mathrm{~kg} / \mathrm{m}^{2}$. All other age groups of Kiribati showed an average $\mathrm{BMI} \geq 30$, indicating obesity.

The weight development within the past year was calculated using the information about the prior weight of the Kiribati crew members during their previous medical fitness tests for nautical services. This analysis showed a distinct increase in body weight in correlation with the duration of their stay on board. The stay on board over 6 and 12 months was associated with an average increase in weight of $4.8 \mathrm{~kg}$ and $5.9 \mathrm{~kg}$.

Blood pressure measurements demonstrated arterial hypertension among $8 \%$ of the Kiribati and $3 \%$ of the European sailors.

\section{Laboratory results}

The results of the lipid profile displayed a similar level of total cholesterol in both groups, however the composition differed (Table 1). The Kiribati showed a significantly lower level of HDL-cholesterol with a calculated median below the recommendations by the DGFF (German Society for Combating Dyslipidemia and its Associated Illnesses; $>40 \mathrm{mg} / \mathrm{dl}$ ). In conclusion, these results revealed significant differences in the non-HDL cholesterol composition.

The uric acid values in the Kiribati were significantly higher than among the Europeans, while there was no difference between both groups concerning fasting blood glucose levels.

\section{Cardiovascular risk}

The cardiovascular risk could be assessed in 78 participating seafarers. According to the above mentioned procedure, a total of 56 sailors $(71.8 \%)$ were grouped into a low-risk group (<3 RF), while 22 subjects $(28.2 \%)$ were assigned to the group with a high cardiovascular risk ( $\geq 3 \mathrm{RF}$ ). Compared to the Europeans, the Kiribati were considerably more often allocated to the high risk group (35.4\% vs. $16.7 \%)$. This difference was slightly attenuated after adjustment for age (22.9\% vs. $13.3 \%)$.

Figure 2 demonstrates the frequency of cardiovascular risk factors in the two different cultural groups. It reveals decreased HDL levels and active smoking as the most frequent risk factors in both groups, especially among the Kiribati, $71 \%$ of whom had low HDL values.

\section{Endurance performance capacity}

All conducted tests were age-adjusted and executed up to at least three increasing stress levels. Four subjects (two from each cultural group) were excluded from the exercise test because of taking a heart rate limiting medication or due to knee dysplasia. The subjective fitness evaluation was similar in both cultural groups. All tested subjects reached around $60-80 \%$ of their individual maximal heart rates. Both cultural groups displayed similar results within each age group, without significant differences. The average $\mathrm{VO}_{2}$ was $39 \mathrm{ml} / \mathrm{kg} / \mathrm{min}$ in

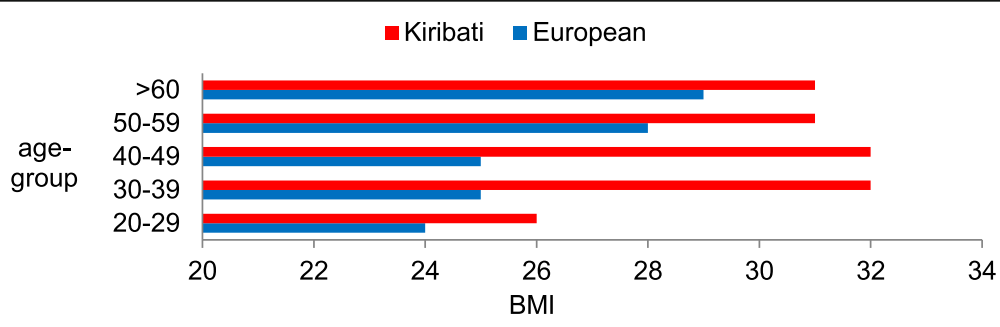

Fig. 1 Age-group related Body Mass Index in Kiribati $(n=48)$ and European $(n=33)$ seafarers 
Table 1 Blood parameters in Kiribati and European seafarers

\begin{tabular}{|c|c|c|c|}
\hline & Kiribati $(n=48)$ & European $(n=29)$ & $p^{\prime}$ \\
\hline \multicolumn{4}{|l|}{ Lipid profile } \\
\hline Cholesterol (mg/dl) (SD) & $159.9(39.8)$ & $157.6(39.7)$ & n.s. \\
\hline$H D L(m g / d l)(S D)$ & $34.9(10.4)$ & $44.8(13.8)$ & 0.002 \\
\hline Cholesterol/HDL (SD) & $4.8(1.4)$ & $3.8(1.5)$ & 0.001 \\
\hline non-HDL cholesterol & $125(29,4)$ & $112,8(25,9)$ & 0.033 \\
\hline$L D L(m g / d l)(S D)$ & $102.3(31.7)$ & $91.5(28.3)$ & n.s. \\
\hline$L D L / H D L(S D)$ & $3.1(1.1)$ & $2.2(0.9)$ & $<0.001$ \\
\hline Triglyceride (mg/dl) (SD) & $114.3(53.9)$ & $110.4(22.1)$ & n.s. \\
\hline \multicolumn{4}{|l|}{ Other } \\
\hline Alkaline phosphatase (U/I) (SD) & $63.4(20.2)$ & $54.1(14.8)$ & 0.031 \\
\hline Uric acid (mg/dl) (SD) & $5.5(1.2)$ & $4.8(1.3)$ & 0.025 \\
\hline Fasting blood glucose (mg/dl) (SD) & 83.2 (15.6) & $81.0(16.1)$ & n.s. \\
\hline
\end{tabular}

${ }^{1}$ Mann-Whitney U Test

Kiribati crew members and $42 \mathrm{ml} / \mathrm{kg} / \mathrm{min}$ among Europeans $(p=0.087)$.

\section{Activity monitoring}

The evaluation of activity showed significantly higher total energy expenditure per day among the Kiribati in comparison to the European seafarers. As shown in Table 2, Kiribati walked an average of 2000 steps more than the Europeans (who more frequently performed administrative duties due to their often higher-rank position on board).

The analysis of working time according to the daily protocols revealed an average of approx. $10 \mathrm{~h}$ a day for both groups, corresponding with a working week of 70 h. The seafarers had a low average sleep duration with $5.5 \mathrm{~h}$ a day.

According to the Perceived Stress Scale, Kiribati were more often assigned to the higher stress-risk group (total sum of 20 points or more) than Europeans (15.2\% vs. $3.2 \% ; p=$ n.s.).

\section{Lifestyle parameters}

The sailors were interviewed on their nutritional behaviour on land and aboard the current cargo vessel. Kiribati often claimed to eat significantly larger amounts of food aboard, while most European sailors stated that they ate less or about the same during their shipboard stay [28].

Concerning cigarette consumption, the Kiribati were more often active smokers than the Europeans (56.3\% vs. $47.2 \% ; p=$ n.s.). When including former smokers, the cigarette consumption of Kiribati seafarers was 17.6 pack years (as opposed to 10.4 pack years among Europeans). Significant differences were noted concerning the alcohol consumption $-19.1 \%$ of the Kiribati claimed to be completely abstinent, while only $3.0 \%$ of Europeans stated that they did not drink alcohol $(p=0.011)$.

In respect of physical activity for strengthening the cardiovascular system, more than $50 \%$ of the sailors did not engage in regular physical activities while ashore or at home. During their stay aboard the cargo vessels, an additional decrease in physical activity in relation to the time

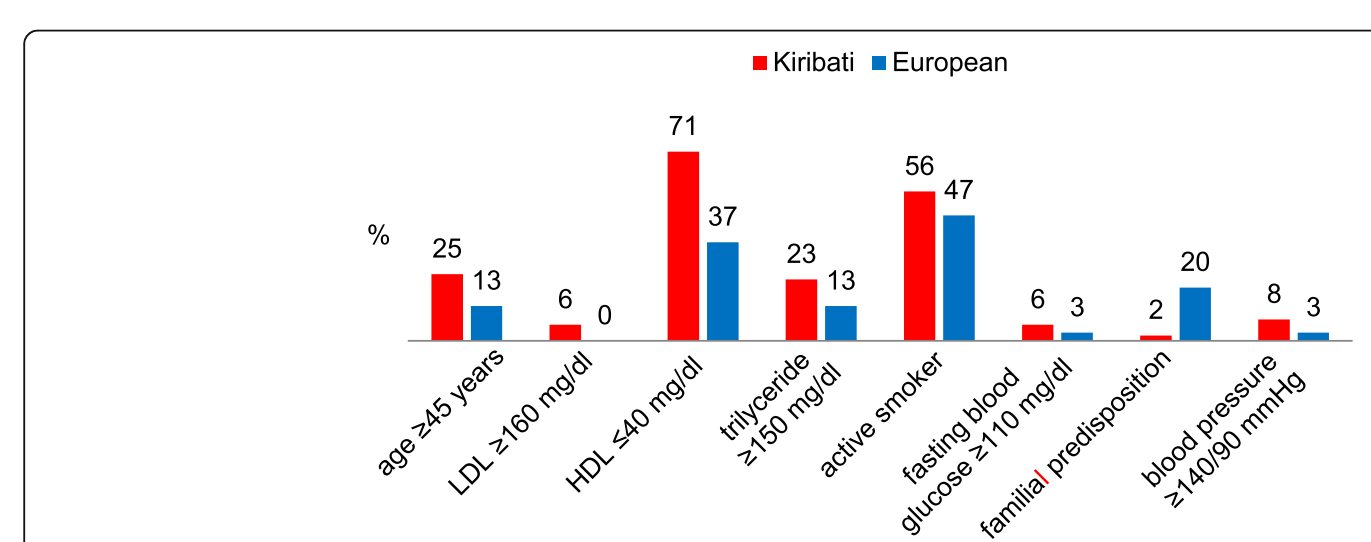

Fig. 2 Prevalence (\%) of cardiovascular risk factors in Kiribati $(n=48)$ and European $(n=29)$ seafarers 
Table 2 Daily activity profiles according to Bodymedia armband monitors and activity protocols

\begin{tabular}{llll}
\hline & Kiribati $(n=46)$ & European $(n=30)$ & $p^{l}$ \\
\hline Total energy expenditure (kcal) (SD) & $3622(465)$ & $3354(583)$ & 0.033 \\
Active energy expenditure (kcal) (SD) & $1315(466)$ & $1142(583)$ & n.s. \\
Daily physical activity (h) (SD) & $4.0(1.7)$ & $3.5(1.9)$ & n.s. \\
Steps (number of) (SD) & $14,209(3716)$ & $12,247(3027)$ & 0.023 \\
Sleeping hours (h) (SD) & $5.2(1.1)$ & $5.8(1.0)$ & 0.038 \\
Working time (h) (SD) & $9.5(1.4)$ & $10.2(1.2)$ & n.s. \\
\hline
\end{tabular}

${ }^{1}$ Mann-Whitney-U-Test

spent doing active sport on land was observed (Kiribati and Europeans 33 and 43\%, respectively; $p=$ n.s.).

\section{Health education}

The need for intensified health education was also estimated differently between the two groups (Fig. 3). This difference was especially striking concerning knowledge about healthy food: while a total of $84.8 \%$ of the Europeans felt well-informed on this issue, only half of the Kiribati stated having an appropriate knowledge.

\section{Discussion}

The evaluation of cardiovascular risks in large population studies (e.g. the PROCAM or Framingham study) usually relies on homogenous (German or American) collectives. Therefore, the application of the respective established risk scores was not suitable for the present multicultural population. In this study, the summation of the eight internationally established cardiovascular risk factors revealed that $28.2 \%$ of the sailors had 3 or more risk factors. Compared to the study results of Oldenburg et al. (2008) (with a percentage of $34.2 \%$ within a collective of 161 sailors) [23], this number is relatively low. Considering only the Kiribati seafarers, $35.4 \%$ had at least three risk factors corresponding to the results of the study mentioned above. Apart from smoking habits, the values most often found were lower HDL and higher triglyceride values and, with that, big differences in nonHDL cholesterol.

In the total group, $68.8 \%$ of the sailors had a BMI $\geq 25$ $\mathrm{kg} / \mathrm{m}^{2}$. This data confirms the results of previous maritime studies describing elevated weight in $66 \%$ of examined seafarers [29]. Also older studies displayed similar results for certain population groups on cargo vessels, where $51.5 \%$ of the European crew members were overweight [6]. This value even lies below average according to the OECD (2012) [13], where a comparison between eastern and western Europeans shows a percentage of 55.0 and $61.3 \%$ respectively.

Among the Kiribati, 91.7\% were classified as overweight. This is also not surprising in view of their larger waist circumference, which correlates highly with cardiovascular risks due to visceral fat distribution [30]. It is necessary to compare the BMI levels of the Kiribati seafarers with the data of the non-seafaring Kiribati ashore (Table 3). Unfortunately, the available data is not stratified according to age groups, but demonstrates at least a general overview of the male adult population [31].

Although Kiribati is already one of the countries worldwide with the highest prevalence of obesity [32], the investigated group aboard had even higher values than the reference population ashore. This result is especially alarming as the examined seafarers belong to an occupational group with high physical efforts. Their relatively high level of physical activity corresponds with

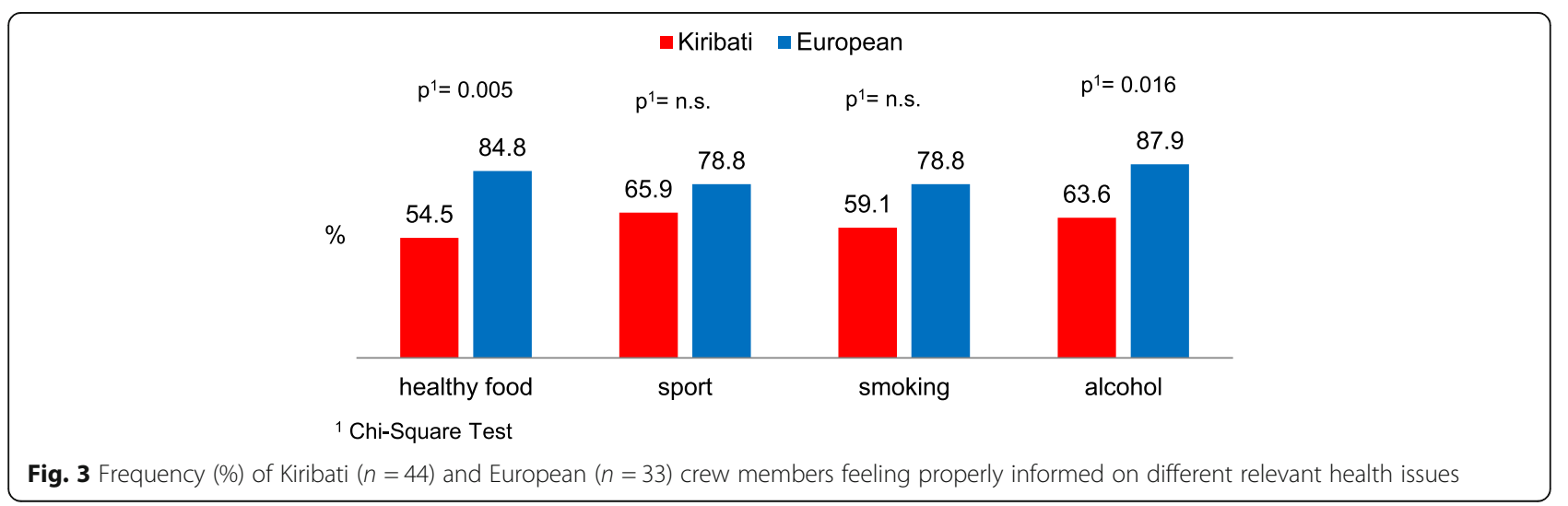


Table $3 \mathrm{BMI}$ of examined Kiribati seamen and the average male Kiribati population ashore ( $\geq 20$ years of age)

\begin{tabular}{lll}
\hline & $\begin{array}{l}\text { Examined Kiribati aboard } \\
\text { ship }(n=48)\end{array}$ & $\begin{array}{l}\text { Kiribati population } \\
\text { ashore }\end{array}$ \\
\hline $\mathrm{BMI} \geq 25 \mathrm{~kg} / \mathrm{m}^{2},(\%)$ & $91.7 \%$ & $76.5 \%$ \\
$\mathrm{BMI} \geq 30 \mathrm{~kg} / \mathrm{m}^{2},(\%)$ & $45.9 \%$ & $39.3 \%$ \\
\hline
\end{tabular}

their high work-related calorie expenditure and thus their verifiably good cardiac fitness level.

The fact that the examined Kiribati subjects between 20 and 29 years in this study were of almost normal weight (with a BMI averaging at $26 \mathrm{~kg} / \mathrm{m}^{2}$ ) suggests that Kiribati seafarers usually are not overweight at the beginning of their career. These values contrast those of non-seafaring young Kiribati ashore with an obesity rate $\left(\mathrm{BMI} \geq 30 \mathrm{~kg} / \mathrm{m}^{2}\right)$ of $47.2 \%$ [12]. This difference is probably caused by a training effect, as the Kiribati sailors have to attend training over a period of at least 18 months in a maritime training centre before their first employment on board. The regular physical training in this centre seems to lead to an almost normal weight among sailors, especially in comparison to the nonseafaring Kiribati population within the same age group.

The weight information (from prior medical fitness tests) proves that Kiribati have a massive gain in weight during the course of their stay aboard the vessels. Many sailors stated that they do less sport during their stay aboard in comparison to the time on land. This supports the development of adiposity and thereby increases the risk of cardiovascular diseases. Due to the distinct increase in weight among Kiribati, it is necessary to place an emphasis on nutritional education, particularly as almost half of the Kiribati (45.5\%) claimed to require information on this issue (Europeans 15.2\%).

Another crucial cardiovascular risk factor on board is smoking. Among the seafarers, $51 \%$ were active smokers. This corresponds with other contemporary studies on sailors' smoking habits [33]. According to statistics from the last couple of years, the percentage of smokers among sailors seems to be decreasing. In the review by Pougnet et al. (2013) [6], 61.3\% of sailors examined in the 1990s were classified as active smokers, while in the 2000 s only a percentage of $45.4 \%$ active smokers was found. The present study documented a larger percentage of active and heavier smokers among the Kiribati crew members in comparison to the Europeans. Cigarettes are still available at very low prices aboard cargo vessels and pose one of the legal intoxicants on board beside alcohol. Monotonous work, loneliness and insufficient health education on board are probable causes for the high prevalence of active smokers among Kiribati.

The documented energy expenditure with an average of $3500 \mathrm{kcal}$ confirms the results of elderly studies by Zorn (1984) [34] and Kierst (1966) [35], in which a sailor working on cargo vessels consumes around 3000 to $3500 \mathrm{kcal}$ when working at average intensity. This is interesting as both comparative studies were conducted at a time when seafaring was regarded to be much more physically demanding than today.

The comparison of the two cultural groups shows that Kiribati have a higher active energy consumption level than European seafarers. This is explainable by the fact that Kiribati, who work only within lower-ranked positions, usually perform more strenuous physical tasks than officers, who are mostly Europeans.

The whole study sample has long working hours on average. The average sleep periods were alarmingly short, especially among the Kiribati crew members. Correspondingly, the Perceived Stress Scale highlights that (particularly the Kiribati) sailors are exposed to an elevated mental stress level, which also represents a cardiovascular risk factor.

At the beginning of the seafarers' career an education in a Kiribati maritime centre has to be completed successfully to prepare the students for the work and live on board. According to the present findings, the Kiribati should be advised during this maritime education also in a healthy lifestyle. Apart from nutritional counselling [8], more physical exercises, anti-drug campaigns and stress prevention are important aspects that can lead to lowering the risk factors for cardiovascular diseases among sailors.

The relatively small number of subjects represents a limitation of this study. On the other hand the participation rate in the present study was very good. Furthermore, the study was limited by examining the crew of only one company; this may limit the external validity of the study. In light of the relatively low number of Kiribati seafarers examined this study can be regarded as a pilot study. Although it is to be feared that it will be hardly possible to find vessels with such high numbers of Kiribati on board, future studies are welcomed with larger populations of Kiribati. In respect of Kiribati seafarers there is a particular need for intervention studies based on the present findings.

Another limitation is the lack of reference values for the Kiribati population. Therefore, culturally specific characteristics could not be considered when comparing the collectives. Thus, further scientific studies concerning the nutritional behaviour and related cardiovascular risks among different cultures of sailors are necessary.

Finally, we cannot exclude the possibility that the reported differences in cardiovascular risk and corresponding nutrition-related parameters are at least in part due to the existing differences in educational level or job position between Kiribati and European seafarers, since cultural background and educational level and job position are inevitably confounded in a seafarer population. This underlines the need for future intervention studies 
to ascertain that changes in life-style behaviour of Kiribati result in changes of cardiovascular risk.

\section{Conclusions}

The present results suggest a higher cardiovascular risk among Kiribati seafarers, with nutritionally related factors (obesity and non-HDL cholesterol) seemingly playing a key role. According to WHO fact sheet No. 394 (2015), a precise dietary change could reduce health risks, such as that for cardiovascular diseases. Therefore, the results of the study confirm the necessity of healthpromoting interventions aboard cargo vessels. Preventive medical care is apparently required in order to educate seafarers in a number of health issues.

\section{Abbreviations \\ BMI: Body-Mass-Index; cm: centimeter; dl: deciliter; DRKS: German Clinical Trials Register; e.g.: exempli gratia (Latin phrase meaning "for example"); et al.: et alii (Latin phrase meaning "and others"); Fig.: figure; g: gram; GmbH: Limited liability company; h: hour; HDL: High density lipoprotein; kcal: large calorie; kg: kilogram; LDL: Low-density lipoproteins; $\mathrm{m}^{2}$ : square meter; mg: milligram; min.: minute; ml: milliliter; $\mathrm{mmHg}$ : millimeters of mercury; n.s.: not specified; No: Number; RF: Risk factors; SD: Standard deviation; Tab.: Table; VO2: Uptake of oxygen; vs: versus; WHO: World Health Organization}

\section{Acknowledgements}

The authors thank all examined seafarers for participating in this voluntary study. Furthermore, we wish to express our gratitude to the Hamburg shipping company for their support and placing four vessels at our disposal. Finally, we thank Claudia Terschüren for checking the statistical concept of this study.

\section{Authors' contributions}

RvK and $\mathrm{MO}$ were responsible for the acquisition, analysis/ interpretation of data and wrote the manuscript. BCZ, BJ, JW, HJJ and VH participated in interpretation of data, drafting the manuscript and revising it critically for important intellectual content. MO planned the study as project leader. RvK organized the data collection and performed the seafarers' examination on board. All authors gave substantial contributions to conception and design of the present study with different focal points (Occupational medicine: $\mathrm{MO}$, RVK, VH; Nutrition: BCZ, BJ; Psychology: JW, HJJ). All authors approved finally the version to be submitted. Each author has participated sufficiently in the work to take public responsibility for appropriate portions of the content.

\section{Funding}

The author(s) received no financial support for the research, authorship, and/ or publication of this article.

\section{Availability of data and materials}

The datasets used and/or analysed during the current study are available from the corresponding author on reasonable request.

\section{Ethics approval and consent to participate}

All personal data were pseudonymised. Participants gave their written consent and the Ethics Committee of the Hamburg Medical Association approved this study. The study was conducted according to good clinical practice based on the Helsinki declaration. The research is also registered within the German Registry of Clinical Studies under the DRKS-ID: DRKS00010819.

\section{Consent for publication}

Not applicable.

\section{Competing interests}

The authors declare that they have no competing interests.

\section{Author details}

Institute for Occupational and Maritime Medicine (ZfAM) Hamburg, Seewartenstr, 10, 20459 Hamburg, Germany. ${ }^{2}$ Preventive Medicine and Nutrition, Institute for Health Services Research in Dermatology and Nursing (IVDP), University Medical Center Hamburg-Eppendorf, Hamburg, Germany. ${ }^{3}$ Medical Clinic and Polyclinic, University Medical Center Hamburg-Eppendorf, Hamburg, Germany. ${ }^{4}$ Competence Center Health, Faculty of Life Sciences, Hamburg University of Applied Sciences, Hamburg, Germany.

Received: 13 February 2019 Accepted: 17 June 2019

Published online: 01 July 2019

\section{References}

1. Filikowski J, Rzepiak M, Renke W, Winnicka A, Smolinska D. Selected risk factors of ischemic heart disease in polish seafarers. Preliminary report. Int Marit Health. 2003;54(1-4):40-6.

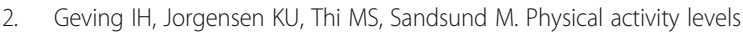
among offshore fleet seafarers. Int Marit Health. 2007;58(1-4):103-14.

3. Oldenburg M, Jensen HJ, Latza $U$, Baur X. The risk of coronary heart disease of seafarers on vessels sailing under a German flag. Int Marit Health. 2010; 62(3):123-8.

4. Fort E, Massardier-Pilonchery A, Bergeret A. Alcohol and nicotine dependence in French seafarers. Int Marit Health. 2009;60(1-2):18-28.

5. Oldenburg M, Baur X, Schlaich C. Occupational risks and challenges of seafaring. J Occup Health. 2010;52(5):249-56.

6. Pougnet R, Pougnet L, Lodde BL, Canals-Pol ML, Jegaden D, Lucas D, et al. Cardiovascular risk factors in seamen and fishermen: review of literature. Int Marit Health. 2013;64(3):107-13.

7. Babicz-Zielinska E, Zabrocki R. Assessment of nutrition of seamen and fishermen. Rocz Panstw Zakl Hig. 1998;49(4):499-505.

8. Lawrie T, Matheson C, Ritchie L, Murphy E, Bond C. The health and lifestyle of Scottish fishermen: a need for health promotion. Health Educ Res. 2004; 19(4):373-9.

9. Zyriax BC, von Katzler R, Jagemann B, Westenhoefer J, Jensen HJ, Harth V, Oldenburg M. Food offerings on board and dietary intake of European and Kiribati seafarers - cross-sectional data from the seafarer nutrition study. J Occup Med Toxicol. 2018;13(9). https://doi.org/10.1186/s12995-018-0190-0 eCollection 2018

10. Oldenburg M. Risk of cardiovascular diseases in seafarers. Int Marit Health. 2014;65(2):53-7.

11. CIBA Foundation Symposium. The origins and consequences of obesity. Derek J. Chadwick, Gail Cardew. 2008;201.

12. Draper $\mathrm{N}$, Marshall $H$. Exercise physiology: for health and sports performance. London: Taylor \& Francis; 2013.

13. Ng M, Fleming T, Robinson M, Thomson B, Graetz N, Margono C, et al. Global, regional, and national prevalence of overweight and obesity in children and adults during 1980-2013: a systematic analysis for the global burden of disease study 2013. Lancet. 2014;384(9945):766-81.

14. OECD. Overweight and obesity among adults: Health at a glance: Europe 2012. OECD publishing; 2012. http://dx.doi.org/10.1787/9789264183896-en

15. Micha R, Khatibzadeh S, Shi P, Fahimi S, Lim S, Andrews KG, et al. Global, regional, and national consumption levels of dietary fats and oils in 1990 and 2010: a systematic analysis including 266 country-specific nutrition surveys. Br Med J. 2014;348:92272.

16. Cohen S, Tyrrell DA, Smith AP. Negative life events, perceived stress, negative affect, and susceptibility to the common cold. J Pers Soc Psychol. 1993;64(1):131-40.

17. Carpenter LL, Tyrka AR, McDougle CJ, Malison RT, Owens MJ, Nemeroff CB, et al. Cerebrospinal fluid corticotropin-releasing factor and perceived earlylife stress in depressed patients and healthy control subjects. Neuropsychopharmacology. 2004;29(4):777-84.

18. Cohen S, Williamson GA. Perceived stress in a probability sample of the United States. In: The social psychology of health. The claremont symposium on applied social psychology. Thousand Oaks: Sage Publications, Inc; 1988. p. 31-67.

19. Diverse Population Collaborative Group. Prediction of mortality from coronary heart disease among diverse populations: is there a common predictive function? Heart. 2002;88(3):222-8.

20. Grundy SM, Balady GJ, Criqui MH, Fletcher G, Greenland P, Hiratzka LF, et al. Primary prevention of coronary heart disease: guidance from Framingham: 
a statement for healthcare professionals from the AHA task force on risk reduction. american heart association. Circulation. 1998;97(18):1876-87.

21. Menotti A, Keys A, Blackburn H, Kromhout D, Karvonen M, Nissinen A, et al. Comparison of multivariate predictive power of major risk factors for coronary heart diseases in different countries: results from eight nations of the seven countries study, 25-year follow-up. J Cardiovasc Risk. 1996;3(1):69-75.

22. Executive summary of the third report of the national cholesterol education program (NCEP). Expert panel on detection, evaluation, and treatment of high blood cholesterol in adults (adult treatment panel III). J Am Med Assoc. 2001;285(19):2486-97.

23. Oldenburg M, Jensen H-J, Latza U, Baur X. Coronary risks among seafarers aboard German-flagged ships. Int Arch Occup Environ Health. 2008;81(6): 735-41.

24. Buckley JP, Sim J, Eston RG, Hession R, Fox R. Reliability and validity of measures taken during the Chester step test to predict aerobic power and to prescribe aerobic exercise. Br J Sports Med. 2004;38(2):197-205.

25. Plowman S, Smith D. Exercise physiology for health, fitness, and performance. 2nd ed. Hagerstown: Lippincott Williams \& Wilkins; 2007.

26. Latin RW, Berg K, Kissinger K, Sinnett A, Parks L. The accuracy of the ACSM stair-stepping equation. Med Sci Sports Exerc. 2001;33(10):1785-8.

27. Fruin ML, Rankin JW. Validity of a multi-sensor armband in estimating rest and exercise energy expenditure. Med Sci Sports Exerc. 2004;36(6):1063-9.

28. Westenhoefer J, von Katzler R, Jensen HJ, Zyriax BC, Jagemann B, Harth V, Oldenburg M. Cultural differences in food and shape related attitudes and eating behaviour are associated with differences of body mass index in the same food environment: cross-sectional results from the seafarer nutrition study of Kiribati and European seafarers on merchant ships. BMC Obes. 2018;5(1). https://doi.org/10.1186/s40608-018-0180-x eCollection 2018.

29. Hansen HL, Hjarnoe L, Jepsen JR. Obesity continues to be a major health risk for Danish seafarers and fishermen. Int Marit Health. 2011;62(2):98-103.

30. Despres JP, Lemieux I, Prud'homme D. Treatment of obesity: need to focus on high risk abdominally obese patients. Br Med J. 2001;322(7288):716-20.

31. Naghavi M, Wang $H$, Lozano $R$, Davis $A$, Liang $X$, et al. Global, regional, and national age-sex specific all-cause and cause-specific mortality for 240 causes of death, 1990-2013: a systematic analysis for the global burden of disease study 2013. Lancet. 2015;385(9963):117-71.

32. Ni Mhurchu C, Rodgers A, Pan WH, Gu DF, Woodward M. Body mass index and cardiovascular disease in the Asia-Pacific region: an overview of 33 cohorts involving 310000 participants. Int J Epidemiol. 2004;33(4):751-8.

33. Hoeyer UL, Hansen HL. Obesity among Danish seafarers. Int Marit Health. 2005;56(1-4):48-55.

34. Zorn E. The Seafarer's food. In: Goethe WH, Watson EN, Jones D, editors. Handbook of nautical medicine. Berlin: Springer; 1984. p. 143-51.

35. Kierst W. Bad effects of improper nutrition during the work on sea. Biul Inst Med Morsk Gdansk. 1966;17(3):393-410.

\section{Publisher's Note}

Springer Nature remains neutral with regard to jurisdictional claims in published maps and institutional affiliations.

Ready to submit your research? Choose BMC and benefit from:

- fast, convenient online submission

- thorough peer review by experienced researchers in your field

- rapid publication on acceptance

- support for research data, including large and complex data types

- gold Open Access which fosters wider collaboration and increased citations

- maximum visibility for your research: over $100 \mathrm{M}$ website views per year

At $\mathrm{BMC}$, research is always in progress.

Learn more biomedcentral.com/submissions 